\section{THE TREATMENT OF FIBROID TUMORS OF THE UTERUS.*}

CHARLES P. NOBLE, M.D.

\section{Surgeon-In-Chief Kensington Hospital for Women.} PHILADELPHIA.

When I addressed the British Gynecological Society ${ }^{1}$ in 1901 on the subject, "The Complications and Degenerations of Fibroid T'umors of the Uterus as Bearing on the Treatment of These Growths," reporting 218 cases, it was with the purpose of pointing out that, in my judgment, the profession had not had a proper estimate of the natural history, degenerations, complications and dangers of fibroid tumors. At that time no one had considered this subject from the standpoint in question. Martin, 1888, had written a paper ${ }^{2}$ reporting the degenerations in the tumors themselves, but ignoring the complications which existed in the particular cases reported. But from 1888 until 1901 the literature shows that no special attention had been paid to this subject, and that the complications of fibroid tumors had attracted practically no attention whatever. It can not be otherwise than gratifying to me that following my own paper on the subject there have been a number of very valuable and careful reports of the individual experience of other surgeors in this field. This is particularly true of the papers of Cullingworth, ${ }^{3}$ Frederick, ${ }^{4}$ Scharlieb $^{5}$ and Hunner. ${ }^{\theta}$

The conclusions of my paper ${ }^{7}$ of 1903 , reporting 258 cases of fibroid tumor, were as follows: It was estimated that because of the degenerations present, 16 per cent. of the patients would have died without operation, and that because of the complications present, 18 per cent. would have died without operation, or a total of 34 per cent. In addition to this a certain number of

* Read to open the discussion on Dr. McDonald's paper, which precedes.

1. Noble, Chas. P.: British Gynec. Jour., 1901, vol. xvil, No. 67 . p. 170: Amer. Jour. Obst., 1901, vol. xliv, No. 3, p. 289.

2. Martin, A.: Centralblatt für Gynäkologie, 1888, p. 389.

3. Cullingworth, C. J.: An Analysis of One Hundred Cases of Uterine Fibrrmyoma, in Which the Condition of the Tumors and the Complications to Which They Had Given Rise Were Verified by Operation, Jour. Obst. and Gynec. British Empire, 1902, vol. i.

4. Wrederick, C. C.: A Study of Uterine Fibromyomata, with Especial Reference to Their Degenerations and Complications as Furnishing Reasons for Early Operations, Amer. Gynec., 1902. vol. i, p. 255.

5 . The following tables from the article by Dr. Mary Scharlleb were received too late for incorporation in the paper, and are published as a footnote for the information of the reader. (An Analysis of One Hundred Cases of Fibromyomata Uteri, Jour Obst, and Gynec., British Empire, 1902, vol. ii, p. 323.

Degenerations of Fibroid Truors ix 100 Constectitre Casms. Edematous and myxomatous. Sarcomatous

Cystic or fibrocysti

Calcareous

Necrotic, infected.

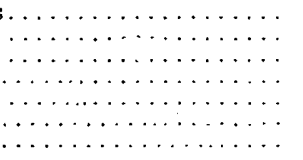

Complcatrons of Fibrotu Tumors in 100 Conshcutive Casks. Cyst or cystomata of one ovary or both ovaries... 23 Thrombosis of veins of lower extremity before

operation
Varicose veins of pelvis $\ldots \ldots \ldots \ldots \ldots \ldots \ldots \ldots$

Varicose veins of pelvis $\ldots \ldots \ldots \ldots \ldots \ldots \ldots \ldots$

Hydrosalpinx Pyosalplnx. double.

Fibroma of fallopian tube.

Paplliomata of the appendages.

Adhesions to viscera.

Adhesions of tumor:

Inflammation of appendix

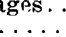

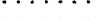

(n)

$\cdots$

$\cdots$

\begin{tabular}{c}
6 \\
. \\
. \\
. \\
\hline
\end{tabular}

51

6. Hanner, Guy L.: One Hundred Consecutive Cases of Myoma of the Uterus. Amer. Medicine, 1903, vol. vi, No. 2, pp. 55-57.

7. Noble. Chas. A.: A Study of the Degenerations and Complications of Fibroid Tumors of the Uterus from the Standpoint of the Treatment of These firowths. Amer. Gynec., 1903. Aprịl. the patients would have died from intercurrent diseases contracted because of the reduced state of health of the patient; in other words, that more than one-third of the women having fibroid tumors which had come under my observation would have died had they not been submitted to operation.

At this date (Jan. 31, 1904) I have operated on 278 patients having fibroid tumors of the uterus. A table of the complications and degenerations encountered in these cases follows. In 180 cases complications or degenerations were present, and in 98 cases no degenerations or complications were recorded. There is no doubt that a good many of the simpler complications and degenerations were not recorded, more especially in the early work. This applies more particularly to edema and to myxomatous degeneration of the tumors. These cases were looked on at that time as instances of soft fibroids, and no note was made of their pathologic condition.

Compracatrons and Drgengrations of Fibroid Tumors COMILE'TED TO JAN. 31, 1904

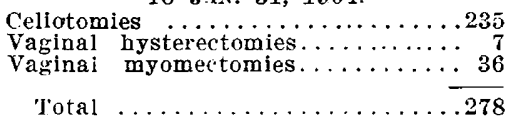

Adenocarcinoma of body of uterus...........

Epitheliomatous infiltration of fibrold tumor aris ing from adenocarcinoma of corpus uteri by Sarcoma

Chorioepithelioma

Myxomatous degeneration of tumor

Cystic degeneration of tumor.

Calcareous infiltration of tumor.

Necrosis of tumor.

Twisted pedicle, pedunculated trimor.

Intraligamentous development of fibroid........

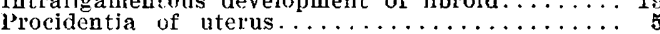

Retroversion of uterus.

Papillarg calcinoma of hoth ovaries $\ldots \ldots \ldots$

Fetopic prewancy.

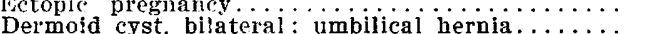

Dermoid cyst. smppurating sinus through abdominal wall. $\ldots \ldots \ldots \ldots \ldots \ldots \ldots \ldots \ldots \ldots \ldots \ldots \ldots$.

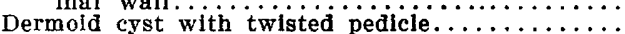

Dermold cyst

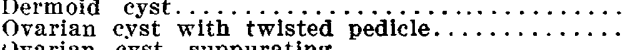

Ovarian cyst, stippurating

Ovarian egst, bilatera!.

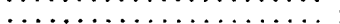

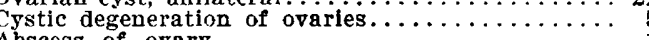

Abscess of ovary $\ldots \ldots \ldots \ldots \ldots \ldots \ldots \ldots \ldots \ldots$

Parovarian cyst.....

Pyosalpinx, unilateral.

Pyosalpinx, unil

Hematosalpinx silateral

Hydrosalpinx, bilateral.

Hydrosalpinx unilate

Salpingitis, bilateral.

Salpingitis, unilateral.....

Abscess of bro

Total 6

It is interesting to compare my own series of cases with that reported by Dr. McDonald. ${ }^{8}$ Of his series of 280 cases there were:

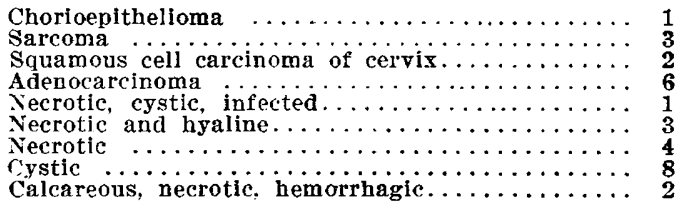

This makes a total of 30 patients who undoubtedly would have died without operation. It is equally certain that a considerable number of the patients having other degenerations would have died.

Of the complications there were:

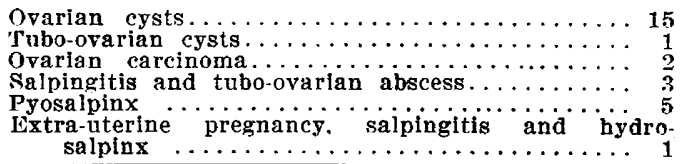

8. McDonald, Filfce: Cornplications and Degenerations of Uterine Fibromyomata. See p. 1344, this issue 
This is a total of 29 that would have died without operation, giving a mortality of 59 in 280 cases, or 21 per cent. This does not include the mortality which would follow the various degenerations not classed as fatal, nor the various complications not necessarily fatal. When these are added, it would bring the mortality in Dr. McDonald's series approximately to that in my own and to that in Frederick's and Cullingworth's.

As illustrating the way these cases run: Since September 15 I have operated on 13 cases, the complications of which are as follows:

1. Salpingitis, submucous fibroid prevlously removed.

2. Uncomplicated

3. Adenomyoma.

4. Uncomplicated

6. Uacomplicated.

6. Calcareous infilt

8. Left hydrosalpinx, right salpingitis

9. Bilateral pyosalpinx.

10. Adenoca rcinoma of body of uterus.

11. Necrotic tnmor, adenocarcinoma of body of uterus

12. Abscess of broad ligament, bilateral salpingitis.

13. Submucous fibrold, sloughing.

This group of cases occurring in three months and a half illustrates the erroneous nature of the old view concerning the innocence of fibroid tumors. Or, to put the matter in a more correct way, it illustrates the fact that women having fibroid tumors are, as a rule, sick women, who have not only fibroid tumors, but other conditions, the complications often being even more serious than the tumors themselves.

Dr. McDonald's tables, those of Cullingworth, Frederick and my own, show the folly of the classical view that women having fibroid tumors of the uterus, as they come under the observation of the gynecologist, are practically well women, suffering but few or no symptoms, and running but little risk as to their health or as to their life. It is begging the question to change the classification and to assert that these women are sick merely because of the complications. The change in classification docs not alter the fact that the women having the fibroid tumors, as they come under observation, are usually sick women. As I have presented this subject before several medical bodies already, I am aware of the objections to the point of view which I hold, and of the statements and arguments of those who claim to be conservative (using the term in its debased instrad of its primary sense) in the treatment of fibroid tumors. As a matter of fact, I believe that these men operate on these cases with cheerful alacrity, but base the indication for operation on the particular complication which may be present. Many of the complications, so far as concern their risks to health or to life, are trifling as compared to the risks of a fibroid tumor. For example, such complications as a parovarian cyst, a retroversion of the uterus with or without adhesions, or cases of appendicitis which have recovered from the acute attack (the so-called interval operation). Every surgeon operates on such cases, although the gravity of the lesions is trifling as compared with the gravity of a fibroid tumor. Patients in whom the tumors are not complicated by other conditions are operated on, as alleged, because of the symptoms which are present-hemorrhage, pain, the presence of a tumor, pressure on the urinary organs or on the alimentary canal, etc. For example, in my table of 278 cases, 180 would be operated on because of the complications present, and the remaining 98 would be operated on because of hemorrhage, pain, the presence of the tumor or pressure on the urinary organs or on the alimentary caral. That is to say, the form of words nsed in stating the indication for operation does not alter the fact that these cases are operated on by surgeons and gynecologists at the present time as a routine matter of practice. ${ }^{\theta}$

Another point to which I wish to call special attention is the relation of fibroid tumors to malignant degeneration and especially to adenocarcinoma of the body of the uterus. In Martin's group of 205 cases there were reported:

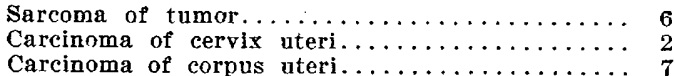

9. Although the position I have taken, with reference to the vature of the indications for operation for fibrold tumors in the various contributions which $I$ have made to the subject, seems to me entirely clear, those who maintain the classical or traditional attitude in their public discussions on the subject have constantly confused it or falled to appreciate it. In order that there may be no doubt about the matter I shall state it in formal terms. The carefully gatbered facts with reference to the life history, the degenerations and the complications of fibroid tumors which are presented in this paper, and have been presented in the previous papers, show that about 16 per cent. of women having fibroid tumors would die if not operated on because of the degenerations and complications arising in the tumor or in the uterus; in other words, that the women having fibroid tumors run a far greater risk of losing their lives by not having them operated on than by submitting themselves to operation. In addition it has been shown that women having fibroid tumors as they present themselves to the gynecologist have, in addition to the tumor itself, many complications outside of the tumor and the uterus. of the women having fibroid tumors, who have come under my observation, about 18 per cent. would have died without operation because of the complications ontside of the tumor and the uterus. This state of facts forms a secondary but an additional reason for operating on women having fiblold tumors, taking them as a class. Taking them as a whole, at least one-third of the women having fibroid tumors, who have come under my observation, would have died had they not been operated on. I hold that the scientific position in reference to the indication for fibroid tumors is that as these facts are incontrovertible being based on careful clinical and patholegic investigation-that the indication for operation should be based on these facts and not on any particular symptom which may be present at the time the woman comes under observation. My position is distinctly in opposition to that which may be called the classical or traditional position, which is, that the operation to remove a fibroid tumor should be done because of the symptoms it is producing at the time the patient presents herself for treatment-whether this be hemorrhage or pain or pressure on the urinary organs. or on the alimentary canal, or whether it is a state of the mind arising in the woman because of her knowledge of the existence of the tumor. Nothing is more variable than symptoms, which can frequently, and indeed, usually, be removed by appropriate treatment. Indeed, the state of the case is even worse than this, for most symptoms it is necessary to take the patient's statement. On the other hand, nothing is more definite than physical facts and pathologic findings. When the two positions are placed in opposition it seems to me there can be no question as to which is the correct one and which should be accepted by the profession. To speak by analogy, a flbroid tumor should be removed for the same reason that an ovarian tumor should be removed; the indication varying in degree, but not in kind. Ovarian tumors are removed, irrespective of the symptoms they are producing, because of onr knowledge of the life history of these growths, which is, that if left to pursue their usual development a fatal result will occur in almost all cases. Similarly, fibroid tumors should be removed, because if left to pursue their usual development, at least in one-third of the cases a fatal result will occur. For those who are convinced that the classical position is correct, I would suggest that one of the strongest arguments that could be produced in support of their position would be to insti. tute a careful research into the autopsy records of well managed instlutions in order to learn, frst, in what proportion of women fibroid tumors are found at autopsy, and second, what relation these tumors had to the state of health or to the death of the particular patients. It is a classical statement that many women live and die without the knowledge that they have had fibrold tumors. This statement I do not believe, but I would be quite willing to be convinced of Its truth on adequate evidence.

It has also been suggested to me that being a gynecologist with a consulting practice, my experience with reference to fibrold tumors is an exceptional one, and that the experience of the family physician is quite different: the difference being that fibroid tumors as he sees them are producino much less mischief than is the case in my experience. At first sight this seems possibly to be a plausible statement. However, I was at one time a family physician myself, and for ten years I had a large experience as attending physician to various dispensaries for the diseases of women, in both of which positions my experience would naturally be the same as that of the family physiclan. Comparing that experience with that of the present $J$ am able to see no difierence whatever; therefore, it is my belier that while this statement sounds plausible, it
is incorrect. 
